The Voluntary Food Intake of Pigs

Occasional Publication No. 13-British Society of Animal Production 1989

edited by J. M. Forbes, M. A. Varley and T. L. J. Lawrence

\title{
DEVELOPMENT OF AN AD LIBITUM FOOD-INTAKE RECORDING SYSTEM FOR PIGS
}

\author{
A. N. R. BROWN \\ Pig Improvement Company, Fyfield Wick, Abingdon OX12 5NA \\ and
}

\section{HENDERSON}

Hunday Electronics, Samson Close, Killingworth, Newcastle NE12 ODX

\section{INTRODUCTION}

$\mathbf{R}^{\mathrm{e}}$ ecording individual food intakes during the performance testing of pigs has always been difficult. Individual penning or penning in groups with individual feeders both have drawbacks from a welfare or cost viewpoint. Additionally, current performance test environments differ radically from commercial rearing environments and there is the danger that performance in the two environments may be poorly correlated.

This paper reports the development of an individual food recording system based on the use of electronic ear tags and a load cell weighing system suitable for pigs in groups over the weight range 25 to $105 \mathrm{~kg}$. Initial design work was carried out by the National Institute of Agricultural Engineering.

\section{MATERIAL AND METHODS}

A number of prototype systems have been built and tested, based on the principle of recognition of electronic transponders and the recording of the weight or a hopper freely suspended from a load cell. Food consumption is recorded for each individual visit and totalled for each pig on a daily basis and used to create a record of food consumption whilst on test.

Trials to date have involved the assessment of accuracy of the prototypes by withdrawing individual meals by hand and comparing recorded weight with actual weight. Trials with up to 15 pigs per station have compared total food weighed into the hoppers with total recorded as consumed.

\section{RESULTS}

\section{Individual meal trials}

Accurracy of the pre-production model has been excellent. Over 100 individual 'meals' (range 80 to $1032 \mathrm{~g}$ withdrawn by hand) the mean difference between recorded weight and actual weight was $0.6 \mathrm{~g}$ with a standard deviation of $8.45 \mathrm{~g}$.

\section{Live animal trials}

Individual trials are conducted by placing a known amount of food (approx. $25 \mathrm{~kg}$ ) in the hopper and recording consumption until all food is consumed. The discrepancy between weighed and recorded quantities varied between $-8.5 \%$ and $+6.5 \%$ with a mean of $1.5 \%$ and s.d. of $2 \cdot 6 \%$ (12 trials, $580 \mathrm{~kg}$ total food consumed).

\section{DISCUSSION}

In practice the statistic that is of most interest is the total amount of food eaten over the total test period. A pig may take up to 20 meals per day, so the accuracy of estimation of any one meal does not need to be particularly good for the total consumption to be known extremely accurately (in the absence of any directional bias). The crucial requirement of any food recording system is that it should be reliable and be able to operate continuously under very adverse conditions. Current development is being directed at this area.

The final system envisages a controller linking eight feed stations (each with 12 to 15 pigs) and down loading data to an IMB PC on a regular basis. The PC may be connected to up to 32 controllers. 